\title{
A política da política industrial: o caso da Lei de Informática
}

Victor Prochnik*

Mateus Lino Labrunie ${ }^{* *}$

Marco Antonio Silveira***

Eduardo Pontual Ribeiro****

\section{Resumo}

Pesquisas econômicas sobre políticas industriais usualmente restringem-se a avaliar os efeitos dos impactos percebidos, relevando a influência de grupos de interesse na sua formulação e aplicação. Cientistas políticos estudam conflitos e acordos entre estes grupos, não os impactos das políticas. Mas, no caso da Lei de Informática, apenas a análise interdisciplinar de trabalhos de economistas e cientistas políticos possibilita compreender seus objetivos, impactos econômicos e as resistências à sua mudança. A Lei resulta, principalmente, de conflitos entre empresários da Zona Franca de Manaus e da Regiāo Sudeste. Tal contexto deve ser observado no aprimoramento desta política industrial, em conjunto com as dimensões econômicas envolvidas.

PalaVras-ChaVe | Política Industrial; Lei de Informática

\section{Código JEL | L52}

* Universidade Federal do Rio de Janeiro (UFRJ) e Instituto Nacional de Ciência e Tecnologia em Políticas Públicas, Estratégias e Desenvolvimento, Rio de Janeiro (RJ), Brasil.. E-mail: victor@ie.ufrj.br

** Universidade Federal do Rio de Janeiro (UFRJ), Rio de Janeiro (RJ), Brasil. E-mail: mateus.labrunie@gmail.com

*** Centro de Tecnologia da Informação Renato Archer (CTI), Campinas (SP) e Faculdade Campo Limpo Paulista (FACCAMP), Campo Limpo Paulista (SP), Brasil. Email: marco.silveira@cti.gov.br

**** Universidade Federal do Rio de Janeiro (UFRJ), Rio de Janeiro (RJ), Brasil. E-mail: eribeiro@ie.ufrj.br 


\section{The politics of industrial policy: the case of the Brazilian Informatics Law}

\section{ABSTRACT}

Economic research on industrial policy is usually restricted to evaluate the efficacy of its perceived impacts, not debating the influence of interest groups. Political scientists study conflicts and agreements behind state action; they do not analyze the impacts of this action. But in the case of the Informatics Law, only the interdisciplinary investigation of economists and political scientists enables the understanding of its real purposes, economic impacts and resistances to change. The Law is mainly the result of a conflict between Manaus Free Trade Area and the Southeast Region entrepreneurs. This context must be observed when proposing developments in this industrial policy, in addition to economic dimensions.

KEYwORDS: Industrial Policy; Informatics Law

JEL-CODE | L52 


\section{Introdução}

A Lei de Informática (L.Info) é o principal benefício fiscal para as empresas de tecnologia da informação no Brasil. Por meio de desonerações do imposto sobre produto industrializado (IPI), tal dispositivo busca estimular o aumento do conteúdo local na produção e da atividade de P\&D no setor de tecnologia da informação. A L.Info data de 1991, mas este artigo aborda apenas suas duas atualizaçôes, em 2001 e 2004.

A L.Info constitui a mais importante política brasileira de incentivo a gastos em P\&D. A renúncia fiscal associada a esta Lei é estimada em quatro bilhōes de reais por ano (BORGES, 2014). No mesmo sentido, Gutierrez (2010, p. 32) afirma que

o faturamento total das empresas beneficiadas pela L. Info correspondeu a aproximadamente $70 \%$ do faturamento das associadas da Associação Brasileira da Indústria Elétrica e Eletrônica (ABINEE) dos segmentos de tecnologias de informação e comunicação (TICs) no mesmo ano, o que dá uma medida da importância de tal lei para esses segmentos.

Todavia, enquanto uma componente central do desenvolvimento econômico é a mudança estrutural, na direção de uma maior participação dos setores mais intensivos em inovação (OREIRO; FEIJÓ, 2010), a indústria de TICs passa por declínio relativo. ${ }^{1}$ A participação do valor agregado (valor da transformação industrial) deste segmento na indústria de transformação diminuiu de 2,9\%, em 2007, para 2,6\%, em 2012 - PIA/IBGE. Entre 1996 e 2013, a participação das exportações de produtos de TICs no total das exportaçóes de produtos industrializados declinou de $3,1 \%$ para $1,5 \%$ - Secex/MDIC.

Diante de tal quadro, esta importante política industrial tem seus resultados contestados. Por um lado, não há dúvidas sobre a necessidade de políticas industriais e de incentivos à inovação e pesquisa e desenvolvimento (P\&D) para o desenvolvimento de uma economia. Por outro lado, a questão de como desenhar e viabilizar politicamente, em uma democracia, sua implantação representa tópico menos explorado na literatura. Este artigo faz um estudo do caso da Lei de Informática (L.Info) por meio de uma metodologia integrada de sua formulação, implantação e das avaliaçōes dos impactos percebidos, para o seu aprimoramento com um olhar interdisciplinar, econômico e de ciência política.

1 Indústria de TICs é o grupo 26 da classificação CNAE 2.0 do IBGE e inclui o segmento de eletrônica de consumo, não beneficiado pela L.Info. 
Há diferenças e complementariedades entre os estudos recentes sobre a L.Info em ciência política, de um lado, e os econômicos, de outro. Nos primeiros, as características das ações dos grupos de interesse formam suas variáveis independentes e os atributos da L.Info compõem as variáveis dependentes. Já os estudos econômicos têm os atributos da L.Info como variáveis independentes e os resultados ou impactos da L.Info como variáveis dependentes.

A análise integrada realizada neste artigo permite contribuir com a literatura, destacando o papel da coalizão de interesses que viabilizou a L.Info para o desenho e a prática desta política industrial. Este mesmo desenho é avaliado, de forma inédita, à luz de programas semelhantes de outros países, mostrando problemas na estrutura de concessão de incentivos na lei brasileira.

A avaliação do atual desenho da L.Info foi tema de trabalhos econômicos, sejam estudos econométricos de impacto (RIBEIRO et al., 2011; KANNEBLEY; PORTO, 2012; CHAVES, 2013), sejam estudos qualitativos (GARCIA; ROSELINO, 2004; GUTIERREZ, 2010; SALLES FILHO et al., 2012; RAMALHO; FERNANDES, 2011). Estes trabalhos apontam necessidades de mudanças na L.Info para aprimorar seus efeitos e mitigar limitações.

Mas a ausência de uma visão ampla, que englobe os aspectos da decisão pública de gênese e sustentação da L.Info, representa os limites da análise mencionada anteriormente, para entender a duração da lei, apesar das deficiências apontadas. Nesse contexto, recuperamos a literatura de ciência política sobre o tema. As limitações podem ser atribuídas à sua origem política, que envolve o confronto entre os interesses dos fabricantes da Zona Franca de Manaus e os de outras regióes, predominantemente do Sudeste (COSTA, 2007; COLOMBO, 2009; CUKIERMAN et al., 2012). A mesma dicotomia é observada na fase de aplicação da L.Info e reforça a análise anterior (MENDONÇA, 2013). Estes trabalhos em ciência política, por sua vez, não se preocupam com os desdobramentos econômicos das suas conclusōes - a Dissertação jurídica de Colombo (2009) é uma exceção.

Portanto, o presente artigo discute a L.Info levando em consideração, conjuntamente, a literatura internacional sobre programas de incentivo à $\mathrm{P} \& \mathrm{D}$, trabalhos brasileiros em economia e em ciência política sobre esta Lei e a evolução da gestão governamental da concessão de incentivos e do acompanhamento da política. $\mathrm{O}$ esforço de unir na análise da política industrial a dimensão econômica e política já foi utilizada por Evans (2004), mas discute um período anterior, as décadas de 1970 e 1980. 
A metodologia adotada aqui afasta-se das usuais análises econômicas de políticas industriais e tecnológicas, cujo foco é a busca por externalidades que, se presentes, podem justificar a intervenção do governo (ACEMOGLU; ROBINSON, 2013). Os autores procuram mostrar que a implantação de políticas econômicas eficientes pode levar a resultados diferentes e mesmo inversos aos esperados por causa da operação das forças políticas. Estes trabalhos desconsideram a viabilidade política das políticas econômicas, exigindo, assim, como realizado neste estudo, uma análise com dois olhares.

Entretanto, os trabalhos sobre políticas econômicas que são exclusivamente econômicos parecem predominar, como se pode depreender, por exemplo, de um exame dos artigos nas revistas e congressos brasileiros. Na prática, o reconhecimento teórico da necessidade de se aliar à ciência política é pouco seguido em economia. Por isso, optou-se por um esforço predominantemente empírico, tendo sido escolhido o caso da L.Info.

Este artigo se desenvolve em mais três seções, além desta introdução e dos comentários finais. Na seção seguinte, descrevem-se a Lei de Informática e a natureza dos embates políticos travados no Congresso Nacional durante os processos de aprovação das suas renovaçôes. A terceira seção, por sua vez, mostra como a aplicação da Lei de Informática, pelo governo federal, está condicionada pelo mesmo embate político apresentado na seção anterior. A quarta seção avalia a L.Info à luz da literatura internacional e de estudos econômicos brasileiros sobre a Lei.

\section{A Lei de Informática e suas renovações}

A L.Info data de 1991 (Lei n. 8248/1991), mas este artigo enfoca apenas suas duas atualizaçôes - as Leis no 10.176, de 2001, e no 11.077, de 2004 -, bem como os trabalhos acadêmicos produzidos entre 2001 e 2014. Os estudos sobre a L.Info na década de 1990 são diferentes dos realizados mais recentemente, porque também discutem o término da política de reserva de mercado, que vigorou na nos anos 1980, as alternativas que se colocaram diante do fim desta política industrial e o processo político de decisão que culminou na L.Info. A maior complexidade deste debate requer um trabalho à parte.

A L.Info foi promulgada em 1991, para estimular a competitividade internacional das empresas de tecnologias da informação e comunicação situadas no Brasil, oferecendo desoneração fiscal em troca da garantia da execução de determinadas 
etapas da produção no Brasil e do investimento em P\&D. A racionalidade econômica por trás da concepção da L.Info envolve uma combinação do conceito de "indústria nascente" com o de "competitividade schumpeteriana”. A indústria é protegida, temporariamente, pela desoneração tributária, enquanto não ganha competitividade. O caminho para a competitividade é visto como sendo, predominantemente, o da introdução e difusão de inovações, para o qual existe a obrigatoriedade de investimentos em P\&D.

A lei contempla produtos de informática, telecomunicações, componentes eletrônicos, software e serviços associados (embora estes dois últimos não recebam benefícios porque não pagam IPI).

Essencialmente, a L.Info oferece desoneração fiscal de $80 \%$ do IPI para as empresas que apresentarem um mínimo de conteúdo local e investirem, em P\&D, $4 \%$ do faturamento dos produtos incentivados. ${ }^{2} \mathrm{O}$ conteúdo local é determinado por projeto de produção para o produto (processo produtivo básico - PPB), indicando que etapas serão realizadas no país.

A L.Info tem outras provisóes secundárias que tratam dos desdobramentos dos condicionantes mencionados anteriormente: ela obriga que parte dos investimentos em P\&D seja realizada em convênios com institutos de pesquisa ou de ensino (universidades), exceto para as empresas menores; e o percentual de isenção do IPI é maior para empresas não localizadas nas Regiōes Sul e Sudeste e para bens de informática e automação de tecnologia nacional, isto é, cujas especificações, projetos e desenvolvimentos tenham sido realizados no país e para produtores de microcomputadores. Também, para estes, permite-se um percentual menor de investimento em P\&D.

Com este desenho, a Lei espera que a desoneração estimule a produção local e que os investimentos em P\&D tornem competitiva a produção protegida.

Todavia, estudos em ciência política alertam que o provável determinante da L.Info seria outro, relacionado às condições de produção no país. Uma interpretação destes estudos sugere que a lei atual é "defensiva”, uma medida compensatória para atender às reivindicações das empresas que não estão na Zona Franca de Manaus (ZFM), de modo a impedir a concorrência desnivelada com as empresas lá instaladas.

Segundo Cukierman et al. (2012), ao fim da vigência da Lei de 1991 (ano 2000 e parte do ano 2001), houve muita pressão dos segmentos empresariais e políticos externos à ZFM, pois os benefícios da L.Info eram e ainda são julgados essenciais para contrabalançar as vantagens concedidas às empresas sediadas naquela Zona

2 Note-se que o investimento em P\&D não necessariamente precisa ser feito nos produtos incentivados e seus processos. 
Franca. Seguiu-se um debate político acirrado entre os deputados do Amazonas, que afirmavam que a continuação da Lei acarretaria a não atratividade da ZFM para a instalação de novas empresas, e deputados de fora da ZFM, principalmente de São Paulo, que pressionavam pela prorrogação da L.Info. Nesse contexto, a atualização da Lei, em 2001, foi aprovada, exprimindo a vantagem política da Região Sudeste sobre a ZFM.

Posteriormente, com o início do governo Lula da Silva, a política industrial voltou a ser importante. Em março de 2004, o governo lançou a Política Industrial, Tecnológica e de Comércio Exterior - PITCE, elegendo quatro setores como estratégicos. No final de 2003, o Ministério da Ciência e Tecnologia havia promovido um seminário de avaliação da L.Info.

Mas estes fatos foram secundários na prorrogação da L.Info, em 2004. Segundo Colombo (2009), deputados ligados ao Estado do Amazonas condicionaram seu apoio à reforma tributária desejada pelo governo à prorrogação da Zona Franca de Manaus até 2023. Políticos de outros estados, por sua vez, só a permitiram quando houve, por compensação, um acordo para a renovação da L.Info até 2019. ${ }^{3}$

Em 2014, houve outra prorrogação da Lei de Informática, novamente como resultado de um acordo político para possibilitar a renovação da Zona Franca de Manaus. Esta, por sua vez, conseguiu sua prorrogação ao se compromissar com interesses eleitorais (DI CUNTO, 2014). A L.Info foi prorrogada sem nenhuma alteração das suas características, apesar da multiplicidade de estudos técnicos e propostas de modificação existentes, muitos dos quais citados neste artigo - ver também Abinee (2013).

A leitura deste processo de aprovação das versões da L.Info aponta ser politicamente inviável alterar tal Lei sem considerar as duas forças mencionadas: as bancadas da Amazônia e de São Paulo e os efeitos de eventuais mudanças da L.Info neste equilíbrio.

A próxima seção argumenta que a manutenção deste conflito político também determina a análise de projetos na aplicação da L.Info.

\section{A aplicação da Lei de Informática}

$\mathrm{O}$ acesso aos incentivos da L.Info requer o cumprimento do processo produtivo básico (PPB). Ele é "o conjunto mínimo de operaçôes [...] que caracteriza a efetiva industrialização de determinado produto" (Lei n. ${ }^{\circ}$ 8.387, de 30/12/1991). Esta exi3 Ver também Costa (2007). 
gência difere dos critérios de política industrial para outras indústrias. Por exemplo, na política para o setor de petróleo e gás, o conteúdo local é definido como um percentual máximo do valor das importações em relação às vendas.

Observe-se que o PPB, ou a alteração de um PPB já estabelecido, é usualmente proposto ao governo. A proposta da empresa, previamente negociada com seus fornecedores, baseia-se nas possibilidades do parque industrial existente. Como as demandas de insumos de um fabricante ou mesmo de um segmento são, em geral, insuficientes para dar escala a um novo produtor de componentes, o PPB é basicamente feito com a capacidade $e$ know how produtivo que já se encontra no país. As modificações possíveis são marginais. Assim, o PPB e o seu cumprimento apenas reproduzem a configuração produtiva da cadeia no país.

$\mathrm{Na}$ prática, o requisito para um possível novo produtor de componentes é ainda maior. A empresa do produto final usualmente monta um kit importado e "A perversa consequência é o fato de um componente produzido localmente não poder acessar esse mercado de montadoras, a não ser que represente um diferencial de custo substantivo, maior que o custo de 'abrir o kit'" (GUTIERREZ, 2010, p. 21).

O processo de decisão do PPB é relacionado ao embate político que deu origem a esta lei. A metodologia de acesso aos benefícios da L.Info é a mesma utilizada pela Zona Franca de Manaus, também baseada na proposição de um PPB e na obrigatoriedade do seu cumprimento. As solicitações de novos PPBs ou alterações em PPBs, referentes tanto a projetos na ZFM como fora dela, são analisadas pelo Grupo de Trabalho do PPB (GT-PPB), formado por representantes da Superintendência da Zona Franca de Manaus, Ministério do Desenvolvimento, Indústria e Comércio Exterior e Ministério da Ciência, Tecnologia e Inovação. Os PPBs são estabelecidos por portarias interministeriais dos dois ministros.

$\mathrm{O}$ PPB é o projeto de um produto e, por isso, em geral é do interesse da indústria como um todo, não apenas de uma empresa. O GT-PPB é formado, centralmente, por um grupo de quatro técnicos, atualmente assessorados por uma equipe de 15 pessoas e as decisões do grupo são tomadas em consenso, o que, como conhecido, dá extremo poder a setores minoritários dentro de um colegiado.

Mendonça (2013), em seu estudo sobre o processo político de decisão do PPB, mostra que o trabalho do GT-PPB é aberto para empresas, associações e sindicatos, da ZFM ou não. Um procedimento recente é a chamada de uma audiência pública para validar o PPB. O autor também verificou que há constante pressão política: "ação de grupos privados organizados, especialmente entidades de classe, na tenta- 
tiva de influenciar nas decisóes, isto é, de mexer no resultado do jogo". A decisão final é do governo.

$\mathrm{Na}$ sua tarefa de analisar projetos de PPBs, o GT-PPB persegue diversos objetivos, como o investimento estimado, emprego gerado, etc. Mas "O efetivamente valorado é o risco de o PPB, ao ser publicado, causar o deslocamento de plantas produtivas de outras regiôes do Brasil para a ZFM, situação que leva ao indeferimento" (MENDONÇA, 2013, p. 7).

Portanto, o embate político que gerou a L.Info prossegue na fase de operacionalização da Lei. A prática de aplicação e gestão dos benefícios da L.Info e da ZFM segue primordialmente o objetivo de uma contínua busca de equilíbrio no enfrentamento que deu origem à L.Info.

\section{Avaliação econômica da Lei de Informática e uma nova avaliação à luz da literatura internacional sobre políticas de incentivo ao P\&D}

Como visto anteriormente, o embate político no Legislativo influenciou não só o desenho da Lei de Informática, mas também a gestão de seu dia a dia. Este desenho e gestão têm o potencial de gerar efeitos positivos ou negativos sobre a inovação e $\mathrm{P} \& \mathrm{D}$, a partir do incentivo ao conteúdo local e ao gasto em P\&D.

Quanto ao conteúdo local, uma resenha da experiência internacional pode ser encontrada em Prochnik (2013). Resulta que, em determinado país, os benefícios de uma política de conteúdo local podem superar seus custos se a política levar à internalização de atividades mais propícias à geração de externalidades, como são as atividades mais intensivas em conhecimento. Mas, no caso da L.Info, como visto, as exigências de conteúdo local não pressionam pela execução de atividades complexas, inviabilizando a geração de externalidades significativas e, em particular, não incentivando o investimento em P\&D, o outro objetivo maior da L.Info.

Políticas de incentivos à atividade de $\mathrm{P} \& \mathrm{D}$ são corriqueiras em muitos países desenvolvidos. Entre os países da OCDE (Organização para Cooperação e Desenvolvimento Econômico), o número dos que dão incentivos públicos a $\mathrm{P} \& \mathrm{D}$ privada aumentou de 12 para 19, entre 1996 e 2005. Desses, 18 concedem incentivo fiscal pelo valor de P\&D feito - a exceção é os Estados Unidos, que dão incentivo apenas à $P \& D$ incremental, isto é, acima de um nível base -, e sete também concedem incentivo fiscal com base no crescimento dos gastos em P\&D (double deduction system) (DUGUET, 2012; BOND; GUCERI, 2012). Desde 2005, cresceu o número de países que concedem estes incentivos. Três trabalhos, sem pretensão de enumerar 
todos os países, avaliam incentivos dados por 24 países da OCDE e por 14 outros (DELOITTE TOUCHE TOHMATSU LIMITED, 2012; EY LLP, 2012; KPMG, 2012).

O número crescente de países que recorrem a estas políticas deve-se à importância dada às inovações para o desenvolvimento econômico e à percepção de falhas de mercado no processo de investimento em P\&D, notadamente os problemas de apropriabilidade das inovações e de restrições de financiamento dos projetos. A questão da apropriabilidade refere-se ao fato de que o conhecimento tem caráter de bem público. Empresas que fazem inovações não conseguem se apropriar inteiramente dos seus benefícios, havendo geração de externalidades positivas para outras empresas, muitas vezes suas concorrentes.

Já o problema de restrições de financiamento está relacionado às assimetrias de informação entre o credor e a corporação que fará a P\&D e ao grau de incerteza relativo à $\mathrm{P} \& \mathrm{D}$, que contribuem para que métodos tradicionais de controle do risco não funcionem bem - há indícios de que a distribuição de lucros provenientes de inovações é tal que não é possível calcular sua variância (HALL; LERNER, 2009). Por esses motivos, os benefícios sociais da inovação são maiores do que os benefícios privados e ambas as falhas de mercado podem levar a um subinvestimento em P\&D em relação ao que seria o melhor para a sociedade, justificando o incentivo fiscal por parte do governo.

Mas não há consenso na literatura quanto aos efeitos das políticas de incentivo ao P\&D. Bronzini e Ianchini (2011) examinaram 11 trabalhos sobre o efeito de subsídios para P\&D e encontraram efeitos positivos apenas em seis. Já David et al. (2000), que analisaram trabalhos econométricos sobre o efeito de subsídios para $\mathrm{P} \& \mathrm{D}$ nos 35 anos anteriores ao seu estudo, mostram que, entre 19 trabalhos, nove não encontraram efeito positivo significativo.

Para comparar a L.Info com suas congêneres de outros países, cabe examinar os efeitos dos dois tipos de benefícios concedidos por estas últimas: incentivos fiscais e subsídios (BUSOM et al., 2012; HALL; VAN REENEN, 2000; DAVID et al., 2000, p. 502).

Incentivos fiscais são normalmente dados a todas as potenciais empresas executoras de P\&D, independentemente da qualidade dos seus projetos, enquanto subsídios dependem da aprovação de um projeto de P\&D pelo governo - o Canadá é uma exceção, pois a concessão de incentivos fiscais também depende da análise de um projeto da empresa pelo governo. Outra diferença é que incentivos fiscais normalmente estão associados a reduções, isenções ou créditos nos tributos pagos 
pelas empresas, enquanto subsídios geralmente são transferências diretas, ou empréstimos a taxas subsidiadas.

Busom et al. (2012) apontam três aspectos de distinção entre incentivos fiscais e subsídios:

- elegibilidade - para subsídios este critério é mais rigoroso do que para incentivos fiscais, pois há necessidade de aprovação do projeto de P\&D pelo governo, que observará características, tais como nível de qualidade, possibilidade de inovaçóes radicais, externalidades, capacidade da firma de fazer aquele projeto e se há colaborações com institutos de pesquisa ou universidades. Dessa forma, subsídios podem viabilizar projetos que trazem benefícios sociais, que não seriam lucrativos na sua ausência. No entanto, como o nível de discricionariedade é alto por parte do governo, esse tipo de incentivo fica sujeito à influência de grupos de pressão. No caso dos incentivos fiscais, como em muitos países a escolha do projeto é deixada para as empresas, estas são mais propensas a escolher projetos em que a taxa de retorno privada seja a mais alta possível, que podem não ser aqueles que teriam altas externalidades positivas e menor retorno privado relativo, inclusive pela questão da apropriabilidade. Esse tipo de incentivo geralmente é mais simples e menos custoso para a empresa, pois independe da elaboração de um projeto e, logicamente, da aprovação deste;

- magnitude e certeza do incentivo - com os subsídios, as empresas sabem exatamente o tamanho do incentivo que receberão, pois são entregues à empresa via transferências diretas, sendo proporcionais ao valor do P\&D feito. Subsídios podem ainda ser customizados para atender ao tipo de dificuldade encontrada pela empresa. A magnitude do incentivo fiscal depende da quantidade de impostos paga, normalmente definida como uma porcentagem de algum determinado imposto, geralmente o imposto de renda. Por um lado, a incerteza é maior, pois não se pode calcular quanto será o incentivo, mas, por outro, a independência da aprovação do projeto pelo governo atenua a incerteza;

- "timing" - subsídios geralmente são anteriores ao projeto, contribuindo para seu financiamento. Incentivos fiscais são recebidos depois que os projetos foram financiados pelas empresas. Assim, subsídios beneficiam pequenas e médias empresas e empresas novas, que têm maior dificuldade para financiar seus projetos de P\&D. Além disso, subsídios são um sinal de confiabilidade do projeto de P\&D para o mercado, facilitando a atra- 
ção de investidores. Por isso, subsídios são indutores do investimento em P\&D, como confirmado por pesquisas empíricas (BUSOM et al., $2012 \mathrm{e}$ ARQUÉ-CASTELLS; MOHNEN, 2012).

Busom et al (2012) também constatam que subsídios também são mais propícios a serem utilizados por empresas com restriçōes ao financiamento. Afirmam, no entanto, que as duas políticas são complementares, e não substitutas entre si. Dados apresentados pelos autores também mostram haver grandes variações no uso desses incentivos entre os países, concluindo que não há consenso na sua utilização.

A L.Info não corresponde perfeitamente a nenhum dos dois tipos de política. A empresa que deseja o incentivo do IPI precisa seguir ou solicitar um PPB, se não houver um para o produto de interesse. Simultaneamente, deve investir em P\&D um valor de aproximadamente $4 \%$ do faturamento líquido da empresa com os produtos incentivados. Desse modo, a L.Info assemelha-se aos subsídios, por exigir a apresentação de um projeto ao governo (embora não seja um projeto de P\&D e sim de produção), e aos incentivos fiscais, por conceder um desconto sobre um imposto.

Com respeito às regras dos programas de incentivo em outros países, podem-se perceber grandes diferenças com relação ao caso brasileiro. A primeira delas é a maneira como os descontos são calculados. Nesses países, o tamanho do desconto é proporcional à quantidade de $\mathrm{P} \& \mathrm{D}$ feita pela empresa (em alguns casos ao seu crescimento), incentivando as empresas a fazerem o máximo possível de P\&D.

No Brasil, como visto, a isenção é predeterminada e sobre um imposto sobre as vendas, o IPI. Também há o requisito de um investimento mínimo em P\&D - 4\% do faturamento dos produtos incentivados. Isso retira a discrição que as empresas podem ter com respeito ao nível de P\&D mais adequado ao seu negócio, além de não diferenciar, por exemplo, o incentivo dado a uma empresa que investe $4 \%$ do seu faturamento em P\&D e a uma que investe $15 \%$, a qual que, segundo os objetivos da política, deveria ser mais incentivada. Esta questão é retomada adiante.

Também, na maioria das políticas de incentivos fiscais dos outros países, caso a empresa não pague imposto ou o imposto pago por ela seja menor do que o desconto oferecido, existe a possibilidade de reembolso, isto é, o governo literalmente dá o dinheiro para a empresa como compensação pelo esforço de P\&D. Esta é uma peculiaridade interessante, pois mesmo empresas já isentas de impostos recebem o incentivo (há limites para tal ação, variando de país para país).

No Brasil, esta possibilidade não existe. Caso os produtos da empresa não paguem IPI, ela não é elegível para o benefício, como o software - embora seja possível que a empresa se candidate a outros benefícios (Lei do Bem, por exemplo). 
Em relação a políticas de subsídios, em outros países as empresas fazem projetos para receber subsídios, oferecidos no início do processo, o que efetivamente financia a atividade de P\&D. No Brasil, como visto, o incentivo é a dedução do IPI, que ocorre posteriormente, na fase de vendas. Como o financiamento ao investimento em $P \& D$ ajuda relativamente mais às pequenas e médias empresas, são estas que mais perdem com a modalidade de apoio prevista na L.Info.

Por fim, a experiência internacional mostra que as políticas de incentivo a P\&D normalmente são mais eficazes para as pequenas e médias empresas, pelos problemas de financiamento encontrados por elas (DUGUET, 2012; CAPPELEN et al., 2012; BOND; GUCERI, 2012; LOKSHIN; MOHLEN, 2012). Este é outro problema da política brasileira, pois a maior parte das empresas beneficiárias da L.Info é de grande porte (RIBEIRO et al., 2011).

Em conclusão, comparando os critérios da L.Info com as diferenças entre incentivos e subsídios concedidos em outros países, enumeradas por Busom et al. (2012), nota-se que a L.Info tende a juntar os problemas dos dois tipos de benefícios e não conter suas vantagens. $\mathrm{O}$ mesmo ocorre em relação às demais características da legislação de outros países, apresentadas nesta seção. Os efeitos são visíveis inclusive no alvo da política de gastos com P\&D.

A L.Info obriga a empresa a gastar em P\&D depois de apresentar um projeto do processo de produção. Mas, se a empresa já possui um projeto de produção, é porque a maior parte da $\mathrm{P} \& \mathrm{D}$ para aquele produto já foi realizada. Assim, os investimentos em $\mathrm{P} \& \mathrm{D}$ referem-se a atividades produzidas em um período posterior àquele em que houve o desenvolvimento do produto incentivado, em geral em outros produtos ou processos. ${ }^{4} \mathrm{O}$ descolamento temporal entre as atividades de $\mathrm{P} \& \mathrm{D}$ geradoras do produto incentivado e as que são realizadas para receber a isenção de impostos também dificulta a fiscalização e impede uma análise da relação custo/ benefício da legislação. Exemplos de descasamento entre projetos de $\mathrm{P} \& \mathrm{D}$ e produção são apresentados em Garcia e Roselino (2004, p. 183) e Gutierrez (2010, p. 34).

Como visto, esta contradição não acontece em outros países, onde os subsídios são anteriores à produção e os incentivos fiscais são proporcionais ao montante de investimento em P\&D. Não sendo uma questão crítica nem para a análise de processos do $\mathrm{PPB}$ nem para a estratégia das empresas, não é surpresa observar que a qualidade do investimento em P\&D fique aquém do esperado. Kannebley e Porto (2012) estimam um modelo de regressão em que a variável dependente é o

4 Uma exceção parcial é a de empresas que desenvolveram o produto no Brasil, pois estas têm direito a uma desoneração fiscal maior. Mas a obrigação de investir em P\&D a posteriori continua. 
pessoal ocupado técnico-científico, representando os gastos em P\&D\&I. Os autores não encontram diferença significativa entre as empresas que recebem benefícios da L.Info e as que não recebem. Com isso, eles concluem que a Lei é anacrônica, dada sua "notória incapacidade de elevar os dispêndios em P\&D\&I, ao menos os internos, dessas firmas”. Já na avaliação de Garcia e Roselino (2004), nos esforços tecnológicos oriundos das exigências da L.Info, predominavam investimentos no desenvolvimento de softwares de baixo valor agregado, principalmente atividades de programação e codificação. Recentemente, Salles Filho et al. (2012) constataram que os investimentos em P\&D têm baixa densidade científica e tecnológica. Este resultado é similar ao encontrado por Prochnik (2013) para a exigência de conteúdo local na exploração e produção na indústria de petróleo e gás.

Esta avaliação difere da primeira avaliação da L.Info feita pelo Ministério da Ciência e Tecnologia em 1999, que destacou seu papel sobre os investimentos em P\&D e sua importância para a competitividade das empresas beneficiadas a partir de uma avaliação impressionista. No entanto, também foram percebidas falhas de formulação na L.Info, tais como a não abrangência do software no $\mathrm{PPB}$, necessidade de maiores esforços para atrair fabricantes mundiais de componentes, etc. (MCTI, 1999).

Por fim, devem-se destacar os efeitos da obrigatoriedade de investir parte dos recursos em universidades e instituiçóes de pesquisa, uma característica comum da política tecnológica brasileira. Figueiredo (2011) critica a restrição desta obrigatoriedade às universidades, mostrando que importantes relacionamentos externos para inovação se dão com outros agentes também (fornecedores de equipamentos e componentes, por exemplo). Entretanto, a simples observação de que recursos estão sendo investidos não permite afirmar que está havendo um desenvolvimento efetivo das regiōes em decorrência desses processos. Por exemplo, Ramalho e Fernandes (2011) mostram que a L.Info é ineficiente para o desenvolvimento regional em Campina Grande, estado da Paraíba, pois não incentiva a criação de laços entre os laboratórios da universidade desta cidade, contratada para projetos de P\&D, pelas regras anteriormente descritas, e as empresas locais. Os investimentos em P\&D estimulam a emergência de cérebros e ideias. No entanto, observa-se a saída do pessoal mais qualificado da região (brain drain), sem vantagens para o seu desenvolvimento.

O desenvolvimento regional orientou uma alteração em 2001, com maior direcionamento dos gastos para regiôes que não São Paulo. Entre 1993 e 2000, o montante de investimentos em $\mathrm{P} \& \mathrm{D}$ atingiu $\mathrm{R} \$ 3$ bilhôes, sendo que dois terços desses investimentos foram concentrados no Estado de São Paulo, o que deu ensejo 
para a inclusão de critérios geográficos na Lei. Posteriormente, houve desconcentração da aplicação de recursos. Por exemplo, entre 1998 e 2008, 53\% dos valores conveniados com instituições de pesquisas em projetos de $\mathrm{P} \& \mathrm{D}$ foram recebidos por instituições nas Regiōes Nordeste/Centro Oeste (40\%) e Sul (13\%) (SALLES FILHO et al., 2012).

O impacto sobre as empresas foi avaliado em dimensões quantitativas de produtividade por Ribeiro et al. (2011) e Chaves (2013), que concluem que as empresas que recebem benefícios da L.Info são menos produtivas do que as que não recebem. Os autores discordam sobre o efeito no crescimento da produtividade, não encontrando efeitos ou apontando aumento, respectivamente.

Em síntese, uma avaliação do desenho do programa mostra suas contradições, necessárias para a acomodação dos vetores políticos que permitiram sua aprovação como política industrial, mas que, à luz da literatura internacional, apontam para dificuldades de alcance de objetivos econômicos de desenvolvimento industrial, como também discutido na literatura citada.

\section{Comentários finais}

Este artigo buscou entender o desenho e efeitos da Lei de Informática (L.Info), com uma metodologia integrada que permitiu primeiro, por meio da literatura de ciência política, entender como os grupos de interesse moldaram o desenho da Lei e sua prática e, segundo, fazer uma análise crítica dos efeitos econômicos da Lei, sobre a inovação e $\mathrm{P} \& \mathrm{D}$ com foco econômico, tanto à luz da literatura nacional sobre o tema, como também com a experiência internacional neste tipo de política industrial. Esta análise integrada possibilitou entender porque a L.Info perdura por tanto tempo, apesar de todas as críticas existentes.

A L.Info resulta do embate político entre os interesses das empresas localizadas fora da Zona Franca de Manaus (ZFM), principalmente as do Estado de São Paulo, e os daquelas situadas na ZFM. As empresas que não estão na ZFM consideram que a competição com as que participam da ZFM só é possível se contarem com as vantagens concedidas pela L.Info. $\mathrm{O}$ confronto político que levou à criação da L.Info também está por trás da gestão pública da concessão de subsídios por ela estabelecidos. O principal critério de análise dos projetos das empresas é o de manter o equilíbrio entre os interesses da ZFM e o das empresas de fora.

A análise das leis de outros países mostrou que suas políticas de incentivos fiscais são acessíveis a todas as empresas apenas após a preparação, discussão e 
aprovação de um complexo projeto, como também é o caso brasileiro. As empresas menores, que mais necessitam da L.Info, têm maior dificuldade na preparação do projeto. Programas de concessão de subsídios no exterior, por sua vez, permitem que empresas recebam os subsídios no início do investimento em P\&D. No Brasil, o apoio é recebido apenas na etapa de vendas. Novamente, as pequenas e médias empresas sofrem relativamente mais com este desenho, pois precisam desenvolver e implantar um produto para posteriormente obter seu financiamento ao investimento em P\&D. Possivelmente, essas vantagens relativas que os programas de incentivo em outros países dão às empresas menores é uma das causas para que no Brasil, ao contrário da norma internacional, a maior parte das empresas aderentes à L.Info seja de grande porte. Havendo capacidade política para modificar a L.Info, ela poderia ser aperfeiçoada ao levar em conta a experiência de outros países na concessão de incentivos e subsídios fiscais. Na configuração atual, a L.Info tende a juntar problemas dos dois tipos de benefícios, não contendo suas vantagens.

Em adição, a análise da L.Info, por sua vez, mostrou que os dois principais requisitos que ela faz às empresas interessadas nos benefícios fiscais, isto é, a exigência de conteúdo local e de investimento em $\mathrm{P} \& \mathrm{D}$, não geram sinergias um para o outro. Por um lado, os PPB não requerem que as empresas façam atividades complexas, aquelas que demandam maiores investimentos em P\&D. Por outro lado, a L.Info não foi planejada de forma a que as empresas venham a fazer investimentos em P\&D nos produtos incentivados, valorizando estes produtos. Para conseguir os benefícios da Lei, as empresas precisam especificar o projeto de produção. Mas, como a atividade de P\&D é um requisito para o desenvolvimento deste projeto, o investimento obrigatório costuma incidir sobre aprimoramentos posteriores do produto ou de outros produtos. A partir destas constataçôes, fazem sentido os estudos econômicos que concluem que os impactos da L.Info são pequenos ou mesmo negativos.

A sustentação dessa Lei fica, neste raciocínio, frágil e surpreende que a mesma não tenha sido alterada. Todavia, com o olhar sobre a concepção e aplicação das políticas governamentais dentro dos seus contextos políticos e culturais, este trabalho procurou mostrar que, do ponto de vista dos seus determinantes políticos, a Lei atende a seus objetivos. Esta forma de sustentação vem mantendo a L.Info sem mudanças significativas, apesar das muitas críticas já formuladas.

Mudanças na Lei passam também pela fase de concessão dos benefícios, em grande parte, superando dificuldades do corpo técnico do Estado, que trabalha em parte de forma "weberiana" (MENDONÇA, 2013) e contra atrasos e problemas de conduta (TCU, 2007; GUTIERREZ, 2010). 
Este panorama vem mudando. Gutierrez (2010) aponta esforços para diminuir a burocracia e demoras no processo, assim como melhorar a fiscalização, como, por exemplo, um sistema de habilitação provisória, que diminuiu de, em geral, um ano, para um mês o prazo para a empresa solicitante iniciar a produção. Além disso, o governo vem recorrendo a critérios de caráter mais estratégicos na decisão dos PPB (MENDONÇA, 2013). Por exemplo, no PPB para os tablets, o governo exigiu a progressiva fabricação local de diversos componentes, inclusive o mais importante deles, os displays (telas de LCD). Houve maior discussão pública em torno do PPB e observou-se uma maior autonomia do governo, em relação às empresas, na sua fixação.

Portanto, existe um embrionário processo de modernização, mas que não é suficientemente forte para promover alteraçôes mais radicais no processo de análise de projetos e, muito menos, para conduzir uma reformatação da L.Info, que seria viabilizado apenas por uma análise concomitante da legislação da ZFM e das bases de apoio político para tal, dados os significativos inter-relacionamentos entre as duas.

Não por acaso, quando a L.Info foi novamente prorrogada pela Lei n. 13.023/14, desta vez por mais dez anos (2019-2029), esta resultou de um acordo no Congresso Nacional para a aprovação conjunta da prorrogação da Zona Franca de Manaus por mais 50 anos (2023-2073). De fato, a aprovação desta última só "foi possível depois que o governo cedeu à pressão de empresários do [...] Sul, Sudeste e Nordeste para fechar acordo que permitiu votar os projetos", isto é, para também incluir e aprovar a prorrogação da Lei de Informática como reportou Di Cunto (2014, p. A7).

\section{Referências}

ACEMOGLU, D.; ROBINSON, J. A. Economics versus politics: pitfalls of policy advice. National Bureau of Economic Research, 2013.

ABINEE - Associação Brasileira das Indústrias Elétrica e Eletrônica. O Brasil na Infoera: impactos da Lei de Informática no país. São Paulo, 2013. Disponível em: <www.abinee. org.br>. Acesso em: 25 nov. 2013.

ARQUÉ-CASTELLS, P.; MOHNEN, P A. Sunk costs, extensive R\&D subsidies and permanent inducement effects. UNU-MERIT, Maastricht University School of Business and Economics, 2012.

BORGES, A. Incentivos da Lei de Informática custam R $\$ 4$ bi por ano, mas falta fiscalização. Valor Econômico, São Paulo, p. A5, 05/03/2014. 
BOND, S.; GUCERI, I. Trends in UK BERD after the introduction of $R \& D$ tax credits. Oxford: Oxford University Centre for Business Taxation, 2012 Disponível em: <http://eureka.bodleian.ox.ac.uk/3192/>. Acesso em 25 nov. 2013.

BRONZINI, R.; IACHINI, E. Are incentives for $R \& D$ effective? Evidence from a regression discontinuity approach. Bank of Italy, May 2011 (Working paper, n. 791). Disponível em: <http://papers.ssrn.com/sol3/papers.cfm?abstract_id=1829994>. Acesso em: 25 nov. 2013. BUSOM, I.; CORCHUELO, B.; ROS, E. M. Tax incentives or subsidies for $R \& D$ ? UNUMERIT Maastricht University, 2012 (Working paper series). Disponível em: <http://ideas. repec.org/p/dgr/unumer/2012056.html>. Acesso em: 25 nov. 2013

CAPPELEN, A.; RAKNERUD, A.; RYBALKA, M. The effects of R\&D tax credits on patenting and innovations. Research Policy, v. 41, n. 2, p. 334-345, 2012.

CHAVES, D. V. DE Á. Industrial policy and self selection: assessing the impact of the informatics law in Brazil. Dissertação (Mestrado em Economia) - Depto. de Economia, Pontifícia Universidade Católica - PUC-RJ, Rio de Janeiro, 2013. Disponível em: <http://www2.dbd. puc-rio.br/pergamum/tesesabertas/1111761_2013_completo.pdf>. Acesso em 25 nov. 2013

COLOMBO, D. G. E. A política pública de incentivo ao setor de informática no Brasil a partir da década de 90: uma análise jurídica. Tese (Doutorado) - Universidade de São Paulo - USP, São Paulo, 2009.

COSTA, S. A. Sobre-representação e interesses regionais: o caso da lei de informática. Dissertação (Mestrado) - Universidade de São Paulo - USP, São Paulo, 2007.

CUKIERMAN, H. L.; DE CASTRO, R. G.; DA SILVA ALVES, L. A. Os debates parlamentares das leis de informática (1984, 1991, 2001, 2004). In: I SIMPÓSIO DE HISTÓRIA DA INFORMÁTICA NA ALC. Medellín, 2012. Disponível em: <http://www.cos.ufrj. br/shialc/content/docs/shialc_2/clei2012_submission_331.pdf>. Acesso em: 25 nov. 2013

DAVID, P. A.; HALL, B. H.; TOOLE, A. A. Is public R\&D a complement or substitute for private R\&D? A review of the econometric evidence. Research Policy, v. 29, n. 4, p. 497-529, 2000.

DELOITTE TOUCHE TOHMATSU LIMITED. Global survey of $R \& D$ tax incentives. New York: Deloitte, 2012. Disponível em: <www.deloitte.com>. Acesso em: 25 nov. 2013 DI CUNTO, R. Câmara prorroga ZFM por 50 anos. Valor Econômico, São Paulo, p. A7, 05/06/2014.

DUGUET, E. The effect of the incremental R\&D tax credit on the private funding of R\&D an econometric evaluation on French firm level data. Revue D'économie Politique, v. 122, n. 3, p. 405-435, 2012. 
EY LLP. Asia-Pacific R\&D incentives. EY, 2012. Disponível em: <http://www.ey.com/Publication/vwLUAssets/2011APAC_RnD/\$FILE/2011-Asia-Pacific-R\&D-incentives.pdf>. Acesso em: 13 mar. 2014.

EVANS, P. Autonomia e parceria: Estados e transformação industrial. Rio de Janeiro: UFRJ, 2004.

FIGUEIREDO, P. N. The role of dual embeddedness in the innovative performance of MNE subsidiaries: evidence from Brazil. Journal of Management Studies, v. 48, n. 2, p. 417-440, 2011.

GARCIA, R.; ROSELINO, J. E. Uma avaliação da Lei de Informática e de seus resultados como instrumento indutor de desenvolvimento tecnológico e industrial. Gestão e Produção, v. 11, n. 2, p. 177-185, 2004.

GUTIERREZ, R. M. V. Complexo eletrônico: Lei de Informática e competitividade. BNDES Setorial, n. 31, p. 5-48, 2010.

HALL, B. H.; LERNER, J. The financing of $R \& D$ and innovation. National Bureau of Economic Research, 2009 (NBER working paper, n. 15325). Disponível em:

<http://www.nber.org/papers/w15325> Acesso em: 12 mar. 2014.

HALL, B.; VAN REENEN, J. How effective are fiscal incentives for R\&D? A review of the evidence. Research Policy, v. 29, n. 4, p. 449-469, 2000.

KANNEBLEY JR., S.; PORTO, G. S. Incentivos fiscais à pesquisa, desenvolvimento e inovação no Brasil: uma avaliação das políticas recentes. Inter-American Development Bank, 2012. Disponível em: <http://ideas.repec.org/p/idb/brikps/76698.html>. Acesso em: 14 mar. 2014.

KPMG INTERNATIONAL. R\&D incentives and services: adding value accross Europe Middle East and Africa. Irlanda: KPMG, 2012. Disponível em: <http://www.kpmg.com/ $\mathrm{CH} /$ en/Library/Articles-Publications/Documents/Tax/pub-20121213-rd-incentives-and-services-ch-en.pdf>. Acesso em: 12 mar. 2014.

LOKSHIN, B.; MOHNEN, P. How effective are level-based R\&D tax credits? Evidence from the Netherlands. Applied Economics, v. 44, n. 12, p. 1527-1538, 2012.

MENDONÇA, M. B. de. O processo de decisão política e a Zona Franca de Manaus. Tese (Doutorado em Administração Pública e Governo) - Fundação Getúlio Vargas, São Paulo, 2013.

MCTI - Ministério da Ciência, Tecnologia e Inovação. Setor de tecnologias da informação: resultados da Lei 8.248/91. Brasília, 1999. Disponível em: <http://www.mcti.gov.br>. Acesso em: 13 mar. 2014. 
OREIRO, J. L.; FEIJÓ, C. A. Desindustrialização: conceituação, causas, efeitos e o caso brasileiro. Revista de Economia Política, v. 30, n. 2, p. 219-232, 2010.

PROCHNIK, V. A política de conteúdo local na indústria de petróleo e gás: o caso dos fornecedores de equipamentos de instrumentação e controle de processos. In: XV ENCONTRO LATINO-IBEROAMERICANO DE GESTÃO DA TECNOLOGIA. Anais... Porto, Portugal: Associação Latino Ibero-Americana de Gestão de Tecnologia, 2013.

RAMALHO, F.; FERNANDES, A. C. Efeitos locais de políticas públicas federais: observações a partir da lei de informática no desenvolvimento do setor de software de Campina Grande. Revista Brasileira de Estudos Urbanos e Regionais, v. 11, n. 1, p. 105-125, 2011.

RIBEIRO, E.; PROCHNIK, V.; DENEGRI, J. Productivity in the Brazilian informatics industry and public subsidies: a quantitative assessment. In: 39० ENCONTRO NACIONAL DE ECONOMIA. Foz do Iguaçu-PR: Anpec, 2011. Disponível em: <http://anpec. org.br/encontro/2011/inscricao/arquivos/000-91b8069bbb7520d179b015637f5ec0b0.pdf>. Acesso em: 25 nov. 2013.

SALLES FILHO, S. et al. Avaliação de impactos da Lei de Informática: uma análise da política industrial e de incentivo à inovacão no setor de TICs brasileiro. Revista Brasileira de Inovação, v. 11, n. especial, p. 191-218, 2012.

SEBASTIAN, F. P. Understanding R\&D policy: efficiency or politics? Review of Economics and Institutions, v. 3, n. 3, 2012. Disponível em: <http://ideas.repec.org/a/pia/review/ v3y2012i3n2.html>. Acesso em: 25 nov. 2013.

TCU - Tribunal de Contas da União. TCU encontra irregularidades na gestão das renúncias de receita da Lei de Informática. Revista do TCU, ano 35, n. 109, p. 121, maio/agosto 2007. Disponível em: <http://portal2.tcu.gov.br/portal/page/portal/TCU/publicacoes_institucionais/periodicos/revista_tcu>. Acesso em: 19 jan. 2015. 